\title{
Social Intelligence of Secondary School Teachers with Respect to Their Gender and Age
}

\author{
Karanam Mahaboobvali ${ }^{1 *}$, Dr. S. Vijaya Vardhini ${ }^{2}$
}

\section{ABSTRACT}

Social intelligence is the ability to compromise so as to understand and manage the people and engage in adaptive social situations. Though everyone needs intelligence in general and Social intelligence in particular. Especially it is essential for the Teachers to interact with the students effectively and for better understanding the students in the school environment. Hence in this context the investigators made an attempt to study the Social intelligence of Secondary school teachers. The objectives of the study are (i) to assess the social intelligence of Secondary school teachers and (ii) to find out the significance difference if any in the Social intelligence of Secondary school teachers due to variations in their Gender and Age. In this study 700 Secondary school teachers were selected from Kadapa district of Andhra Pradesh by employing simple random sampling technique. In this study the researchers analyzed the Social intelligence of Secondary school teachers in relation to their Gender and Age and found that, there is no significant difference between the male and female sample in their Social intelligence. On the other hand findings revealed that, there is significance difference among the age group of Secondary school teachers in their Social intelligence in general and Patience, Cooperativeness, Confidence, Sensitivity, Recognition of Social Environment, Tactfulness and Memory dimensions of Social intelligence in specific. Findings of the study are (i) both the male and female Secondary school teachers expressed equal level of Social intelligence and (ii) significant variation exists among the age groups of the Secondary school teachers towards the Social intelligence in Toto.

Keywords: Intelligence, Social intelligence, School environment and Secondary school teachers.

Man is a social animal is an early saying of our ancestors, this statement reveals that man is mainly dependent on his society. For well being, effective survival and existence in the society one should required intelligence in general and Social intelligence in particular. Social intelligence is the ability to understand others and act wisely in human relations (Thorndike).

\footnotetext{
${ }^{1}$ Research Scholar, Dept. of Education, Dravidian University, Kuppam, Andhra Pradesh

${ }^{2}$ Assistant Professor, Dept. of Education, Dravidian University, Kuppam, Andhra Pradesh *Responding Author (C) 2016 I K Mahaboobvali, S Vardhini; licensee IJIP. This is an Open Access Research distributed under the terms of the Creative Commons Attribution License (http://creativecommons.org/licenses/by/2.0), which permits unrestricted use, distribution, and reproduction in any Medium, provided the original work is properly cited.
} 


\section{Social Intelligence of Secondary School Teachers with Respect to Their Gender and Age}

Social intelligence is the ability to understand and manage with the men and women; boys and girls and to act wisely in human relations. Social intelligence is the part of the individual's mental ability which generates the capacity to adapt him to the society; as such relations are essential for his/her existence. It is the human capacity to understand what is happing in the world and respond to that understanding in personally and socially in effective manner. Especially Social intelligence is essential for the Teachers to interact with the students effectively and for better understanding the students in the school environment.

The level of Social intelligence differs among individuals and high Social intelligence possessed persons are able to handle the people well. As per the studies carried out by Sembiyan. R and Visvanathan. G (2012), Sumamlata Saxene and Rajat Kumat Jain (2013), Agata Maltese et.al. (2012), Ruchi Thakur, Shubhanaganna Sharma and Raj Pathania (2013), Ramesh Singh Bartwal (2015) it is observed that there are many external and internal variables/factors which affects the level of Social intelligence.

It is observed from the existing literature that, very few studies were conducted by the researchers on Social intelligence of School teachers especially on Secondary School teachers. From the existing studies Social intelligence is identified as a gray area in the field of educational research. As Social intelligence is essential for the Teachers to interact with the students (Preadolescent and adolescent) effectively and for better understanding the students in the school environment the researchers felt to carried out this study. Hence in this context investigators made an attempt to study the Social intelligence of Secondary school teachers.

\section{METHODOLOGY}

\section{Objectives:}

The objectives of the study are:

(i) To assess the Social intelligence of Secondary school teachers with respect to (a) Patience (b) Cooperativeness (c) Confidence (d) Sensitivity (e) Recognition of Social Environment (f) Tactfulness (g) Sense of humor (h) Memory dimensions and in total.

(ii) To find out the significance difference if any in the Social intelligence of Secondary school teachers due to variations in their Gender and Age.

\section{Hypotheses:}

To study the present problem the researchers formulated the following hypotheses.

$\mathrm{H1}$ : There is significance difference in the Social intelligence of Secondary school teachers due to variation in their Gender.

$\mathrm{H} 2$ : There is significance difference in the Social intelligence of Secondary school teachers due to variation in their Age.

\section{Method:}

Keeping in view the objectives and scope of the present study the investigators adopted survey method to carry out this research. 


\section{Social Intelligence of Secondary School Teachers with Respect to Their Gender and Age}

\section{Sample:}

The population of the present research study is Secondary school teachers. In this problem the investigators selected 700 Secondary school teachers who are working in Govt., Z.P. and Municipal schools located in Kadapa district of Andhra Pradesh by employing Simple random sampling technique.

\section{Tool:}

In this investigation the investigators adapted Social intelligence scale which is developed by Chadda. N.K. and Usha Ganesh Delhi with very slight modifications. This scale consists of 66 items. These items were grouped under 8 dimensions i.e. (a) Patience (b) Cooperativeness (c) Confidence (d) Sensitivity (e) Recognition of Social Environment (f) Tactfulness (g) Sense of humour and (h) Memory. This tool has constructive, Content, Face and Intrinsic validity and reliability. Both the English and translated Telugu versions of the Social intelligence scale was administered to the sample for collecting required necessary data to study the present problem.

\section{Statistical techniques:}

To analyze the collected data the investigators Mean, SD, " $\mathrm{t}$ ” and ' $\mathrm{F}$ ' ratios statistical techniques were employed.

\section{RESULTS AND DISCUSSIONS}

The obtained results from the analysis were presented and discussed hereunder in two parts.

\section{Part-1: Social intelligence and Gender}

It is observed from table no. -1 that the calculated t-value for the total scale (1.037) is less than the table value of 1.96 and not significant at 0.05 level. It is depicted from the results that, there is no significant variation between the Mean and SD scores of the male and female Secondary school teachers to the total scale and all the 8 dimensions of Social intelligence scale and computed t-values are also not significant at 0.05 level of significance.

Hence the hypothesis "there is significance difference in the Social intelligence of Secondary school teachers due to variation in their Gender" is rejected for all the dimensions of the scale and for the total scale also. Therefore it is concluded that both male and female Secondary school teachers do not have any significant difference on their Social intelligence. 
Social Intelligence of Secondary School Teachers with Respect to Their Gender and Age

Table No.-1: Mean, SD and t-values of the Secondary school teachers for the Social Intelligence scale with respect to their Gender

\begin{tabular}{|c|c|c|c|c|c|c|}
\hline & Social Intelligence & Gender & $\mathbf{N}$ & Mean & SD & $\begin{array}{c}\text { Calculated } \\
\text { 't 'value }\end{array}$ \\
\hline \multirow{2}{*}{ A } & \multirow{2}{*}{ Patience } & Male & 350 & 19.37 & 2.255 & \multirow{2}{*}{ 1.789@ } \\
\hline & & Female & 350 & 19.67 & 2.138 & \\
\hline \multirow{2}{*}{$\mathrm{B}$} & \multirow{2}{*}{ Cooperativeness } & Male & 350 & 24.75 & 2.480 & \multirow{2}{*}{ 0.590@ } \\
\hline & & Female & 350 & 24.86 & 2.519 & \\
\hline \multirow{2}{*}{$\mathrm{C}$} & \multirow{2}{*}{ Confidence } & Male & 350 & 19.28 & 2.366 & \multirow{2}{*}{ 0.220@ } \\
\hline & & Female & 350 & 19.32 & 2.097 & \\
\hline \multirow{2}{*}{$\mathrm{D}$} & \multirow{2}{*}{ Sensitivity } & Male & 350 & 20.72 & 2.643 & \multirow{2}{*}{ 1.789@ } \\
\hline & & Female & 350 & 21.07 & 2.554 & \\
\hline \multirow{2}{*}{$\mathrm{E}$} & \multirow{2}{*}{$\begin{array}{c}\text { Recognition of Social } \\
\text { Environment }\end{array}$} & Male & 350 & 1.39 & 0.627 & \multirow{2}{*}{ 0.992@ } \\
\hline & & Female & 350 & 1.43 & 0.591 & \\
\hline \multirow{2}{*}{$\mathrm{F}$} & \multirow{2}{*}{ Tactfulness } & Male & 350 & 3.24 & 1.209 & \multirow{2}{*}{ 0.553@ } \\
\hline & & Female & 350 & 3.19 & 1.111 & \\
\hline \multirow{2}{*}{$\mathrm{G}$} & \multirow{2}{*}{ Sense of Hummer } & Male & 350 & 3.56 & 1.298 & \multirow{2}{*}{ 0.320@ } \\
\hline & & Female & 350 & 3.59 & 1.296 & \\
\hline \multirow{2}{*}{$\mathrm{H}$} & \multirow{2}{*}{ Memory } & Male & 350 & 9.95 & 1.649 & \multirow{2}{*}{ 1.826@ } \\
\hline & & Female & 350 & 9.71 & 1.863 & \\
\hline \multirow{2}{*}{\multicolumn{2}{|c|}{ Total }} & Male & 350 & 18.14 & 2.619 & \multirow{2}{*}{ 1.037@ } \\
\hline & & Female & 350 & 17.93 & 2.845 & \\
\hline
\end{tabular}

$@=$ not significant at 0.05 level, Table value for $t$-test at 0.05 level=1.96

These findings are supported by the findings of Ramesh Singh Bartwal (2015) and contrary with the findings of Sembiyan. R and Visvanathan. G (2012) and Ruchi Thakur et. al. (2013). Studies of Sumamlata Saxene and Rajat Kumat Jain (2013) revealed that female respondents posses more Social intelligence than male. Contrary Agata Maltese et.al. (2012) found that girls have more social cognitive abilities than that of boys, conversely boys show better social behavioural competences. In majority of traits and psychological and social aspects women are productive 


\section{Social Intelligence of Secondary School Teachers with Respect to Their Gender and Age}

and perform equally with the men, so in the present study there is no significant difference is observed between the male and female Secondary school teachers in their Social intelligence.

\section{Part-2: Social intelligence and age}

To find out the significant difference in the Social intelligence of Secondary school teacher among the age groups, one way ANOVA technique is used and to know the significance difference within/between the age groups Mean, S.D. and t-values were computed for the total scale and each dimension of the scale. The obtained results are shown in table no.-2.

It is obvious from the table no.-2, that the computed F-ratio for the total scale (5.488) is significant at 0.01 level and the formulated hypothesis is accepted. Hence, there exists significant variation exists among the age groups of the Secondary school teachers towards the social intelligence in Toto. The t-values t 1.2 ('below to 30 years' and 'between 31 to 45 years') and t 1.3 ('below to 30 years' and ' 46 years and above') revealed that there is significant difference between the age groups 'below to 30 years' and 'between 31 to 45 years' age groups and 'below to 30 years' and ' 46 years and above' age groups of sample. From the total Mean scores it is found that, sample who are 'below to 30 years' and '46 years and above' age groups possessed the higher level of Social intelligence than the teachers of 'between 31 to 45 years' age group.

It is clear from the F-ratios of the respondents to the dimensions of Social intelligence scale namely, Patience, Cooperativeness, Confidence, Sensitivity and Memory (16.616, 25.657, 12.413, 34.977 and 6.902 respectively) are significant at 0.01 level and the dimension Recognition of Social Environment (3.442) is significant at 0.05 level. Therefore there is significant disparity in the Social intelligence of Secondary school teachers among their age groups with regards to the dimensions namely, Patience, Cooperativeness, Confidence, Sensitivity, Recognition of Social Environment and Memory. The respondents exhibited no significance difference for the dimensions Tactfulness and Sense of Hummer.

For the Patience dimension it is found that, three age groups of sample demonstrated significance difference in their Social intelligence (t 1.2: 2.009; t 1.3: 2.009 and t 2.3: 5.915). Secondary school teachers of ' 46 years and above' age group hold high Social intelligence than their counter parts for the same dimension.

From the t-values (t 1.2 and t 2.3) of dimensions Cooperativeness and Sensitivity it is clear that, sample established significance difference between the age groups in their Social intelligence ( $\mathrm{t}$ 1.2: 4.126 and 4.312 and t 2.3: 6.894 and 8.297 respectively). For the same dimensions '46 years and above' age group respondents showed greater Social intelligence than other age groups. Likewise for the Confidence and Memory dimensions sample determined significance difference between the 'between 31 to 45 years' and ' 46 years above' age groups in their Social intelligence (t 2.3: 5.024 and 3.704). From the mean scores it is found that, '46 years and above' age group sample confirm better Social intelligence than other two age groups for Confidence and Memory dimensions. 
Social Intelligence of Secondary School Teachers with Respect to Their Gender and Age

Table No.-2: Mean, SD, F-ratios and t-values of the Secondary school teachers for the Social Intelligence scale with respect to their Age

\begin{tabular}{|c|c|c|c|c|c|c|c|c|c|}
\hline \multicolumn{2}{|c|}{ Social Intelligence } & \multicolumn{2}{|c|}{ AGE } & \multirow{2}{*}{\begin{tabular}{|l|}
$\mathbf{N}$ \\
109 \\
\end{tabular}} & \multirow{2}{*}{\begin{tabular}{|l|} 
Mean \\
19.54 \\
\end{tabular}} & \multirow{2}{*}{\begin{tabular}{|l|} 
S.D. \\
2.433 \\
\end{tabular}} & \multirow{4}{*}{$\begin{array}{l}\text { F-Ratio } \\
16.616 * *\end{array}$} & \multicolumn{2}{|c|}{ t-value } \\
\hline \multirow{4}{*}{ A } & \multirow{4}{*}{ Patience } & 1 & Below to 30 years & & & & & & \\
\hline & & 2 & Between 31 to 45 years & 302 & 19.01 & 2.111 & & t 1.2 & $2.009 *$ \\
\hline & & 3 & 46 years and above & 289 & 20.03 & 2.085 & & $\mid \begin{array}{ll}t & 1.3 \\
t & 23\end{array}$ & $\begin{array}{l}2.009^{*} \\
5015 * *\end{array}$ \\
\hline & & \multicolumn{2}{|c|}{ Total } & 700 & 19.52 & 2.201 & & & \\
\hline \multirow{4}{*}{ B } & \multirow{4}{*}{ Cooperativeness } & 1 & Below to 30 years & 109 & 25.11 & 2.170 & \multirow{4}{*}{$25.657 * *$} & & \\
\hline & & 2 & Between 31 to 45 years & 302 & 24.06 & 2.531 & & t 1.2 & 4.126** \\
\hline & & 3 & 46 years and above & 289 & 25.46 & 2.377 & & $\mid \begin{array}{ll}t & 1.3 \\
t & 33\end{array}$ & 1.328@ \\
\hline & & \multicolumn{2}{|c|}{ Total } & 700 & 24.80 & 2.498 & & & \\
\hline \multirow{4}{*}{$\mathrm{C}$} & \multirow{4}{*}{ Confidence } & 1 & Below to 30 years & 109 & 19.14 & 2.451 & \multirow{4}{*}{$12.413 * *$} & & \\
\hline & & 2 & Between 31 to 45 years & 302 & 18.90 & 2.144 & & $\mid \begin{array}{l}t \\
+1.2\end{array}$ & 0.906@ \\
\hline & & 3 & 46 years and above & 289 & 19.79 & 2.153 & & $\mid \begin{array}{ll}t \\
+2.3\end{array}$ & 2.575@ \\
\hline & & \multicolumn{2}{|c|}{ Total } & 700 & 19.30 & 2.234 & & & \\
\hline \multirow{4}{*}{$\mathrm{D}$} & \multirow{4}{*}{ Sensitivity } & 1 & Below to 30 years & 109 & 21.25 & 2.622 & \multirow{4}{*}{$34.977 * *$} & \multirow{4}{*}{$\begin{array}{l}\mathrm{t} 1.2 \\
\mathrm{t} 1.3 \\
\mathrm{t} 2.3\end{array}$} & \multirow{4}{*}{$\begin{array}{l}\text { 4.312** } \\
1.547 @ \\
\text { 8.297** }\end{array}$} \\
\hline & & 2 & Between 31 to 45 years & 302 & 20.01 & 2.389 & & & \\
\hline & & 3 & 46 years and above & 289 & 21.69 & 2.530 & & & \\
\hline & & \multicolumn{2}{|c|}{ Total } & 700 & 20.90 & 2.603 & & & \\
\hline \multirow{4}{*}{$\mathrm{E}$} & \multirow{4}{*}{$\begin{array}{l}\text { Recognition } \\
\text { of Social } \\
\text { Environment }\end{array}$} & 1 & Below to 30 years & 109 & 1.55 & 0.585 & & & \\
\hline & & 2 & Between 31 to 45 years & 302 & 1.38 & 0.579 & 1 & & $\begin{array}{l}2.653^{* *} \\
2011 *\end{array}$ \\
\hline & & 3 & 46 years and above & 289 & 1.39 & 0.643 & 3.4 & $\mid \begin{array}{ll}t & 1.3 \\
+2 & 3\end{array}$ & \\
\hline & & To & & 700 & 1.41 & 0.609 & & & \\
\hline & & 1 & Below to 30 years & 109 & 3.25 & 1.115 & & & \\
\hline & & 2 & Between 31 to 45 years & 302 & 3.23 & 1.163 & & $\mid \begin{array}{ll}t \\
t \\
+12\end{array}$ & 0.153@ \\
\hline $\mathrm{F}$ & 1 actfulness & 3 & 46 years and above & 289 & 3.20 & 1.178 & 0.094@ & & \\
\hline & & To & & 700 & 3.22 & 1.161 & & & \\
\hline & & 1 & Below to 30 years & 109 & 3.67 & 1.299 & & & \\
\hline$C_{-}$ & Sense & 2 & Between 31 to 45 years & 302 & 3.47 & 1.385 & & 1 & 1.328@ \\
\hline $\mathrm{G}$ & Hummer & 3 & 46 years and above & 289 & 3.65 & 1.193 & 1.666@ & & 0.165@ \\
\hline & & To & & 700 & 3.58 & 1.297 & & & \\
\hline & & 1 & Below to 30 years & 109 & 9.84 & 1.722 & & & \\
\hline & & 2 & Between 31 to 45 years & 302 & 9.56 & 1.861 & & & $\begin{array}{l}1.425 \\
1.250\end{array}$ \\
\hline $\mathrm{H}$ & Memory & 3 & 46 years and above & 289 & 10.10 & 1.630 & 6.902 & & 1.359@ \\
\hline & & To & & 700 & 9.83 & 1.762 & & & \\
\hline & & 1 & Below to 30 years & 109 & 18.31 & 2.602 & & & \\
\hline & tal S & 2 & Between 31 to 45 years & 302 & 17.64 & 2.957 & & & $\begin{array}{l}2.21 \\
0.08\end{array}$ \\
\hline & tal scale & 3 & 46 years and above & 289 & 18.34 & 2.488 & 5.488 & & \\
\hline & & To & & 700 & 18.03 & 2.734 & & & \\
\hline
\end{tabular}

@ $=$ not significant at 0.05 level $*=$ Significant at 0.05 level ${ }^{* *}=$ Significant at 0.01 level

Table value for F-ratio at 0.05 level=3.01 and at 0.01 level $=4.65$

Here: t 1.2: t-value of 'below to 30 years' and 'between 31 to 45 years' age groups

t 1.3: t-value of 'below to 30 years' and ' 46 years and above' age groups

t 2.3: t-value of 'between 31 to 45 years' and ' 46 years above' age groups 


\section{Social Intelligence of Secondary School Teachers with Respect to Their Gender and Age}

In the Recognition of Social Environment age groups sample 'below to 30 years' and 'between 31 to 45 years' (t 1.2: 2.653) and 'below to 30 years' and '46 years and above' (t 1.3: 2.211) established significance difference between the age groups in their Social intelligence and 'below to 30 years' age group possessed the higher level of Social intelligence than the teachers of other two age groups.

Findings of Ruchi Thakur, Shubhanaganna Sharma and Raj Pathania (2013) are supported the findings of the present work. As age increases human interaction with the society and experience will also increases. Through the experience one can gain the diversified knowledge and enlightenment. Through this Social intelligence also increases. Hence, the Secondary school teachers aged '46 years and above' may demonstrated higher Social intelligence than other two age groups with regard to all the dimensions except Tactfulness and Sense of Hummer.

\section{FINDINGS}

Findings of the present study are:

- Both the male and female Secondary school teachers expressed equal level of Social intelligence.

- Significant variation exists among the age groups of the Secondary school teachers towards the Social intelligence in Toto.

- Sample who are 'below to 30 years' and '46 years and above' are possessed the higher level of Social intelligence than the sample of 'between 31 to 45 years' age for total scale.

- There is significant difference in the Social intelligence of Secondary school teachers among their age groups with regards to all the dimensions Social intelligence except Tactfulness and Sense of Hummer.

- Teachers working in Secondary schools of '46 years and above' age group demonstrated higher Social intelligence than their counter parts for the dimensions Patience, Cooperativeness, Confidence, Sensitivity and Memory.

\section{CONCLUSION}

School is a miniature society which consist students of different ages, religions, race, castes, creeds, languages, cultures, intelligence levels, attitudes, aptitudes, abilities, capacities, perception, adjustment, personalities and so on. In this context teacher's role is very crucial. Teacher profession is very dignified profession in the society, teachers were considering as role models and teachers will mould the future citizens in his/her class room with his efforts and abilities. The future of any nation will build in the class room in the hands of competent, socially adjusted and good mental health teachers. At this juncture Social intelligence is essential for the Teachers to interact and understand the students effectively in the school environment. So teacher educators and teacher education institution should take further steps in inculcating and improving the Social intelligence among the pre-service and in-service teachers. Social intelligence should be included as one component of the curriculum in all levels of the Teacher education programmes and one practicum component may be designed with regards to 


\section{Social Intelligence of Secondary School Teachers with Respect to Their Gender and Age}

developing the Social intelligence among the students and student teachers. There are very few suitable and worthy tools are available to investigate the Social intelligence, hence it very much essential to develop the culture fair, reliable and valid research tools. There are very less number of studies were done in this area so, Governments, NGOs, Research organizations, Stakeholders should take further steps in conduct researches on Assessment of Social intelligence among the various age groups of students, teachers and other public and private sector people for developing better society with good Social intelligence.

\section{REFERENCES}

Agata Maltese, Marianna Alesi and Azzura giureppe Maria Alu (2012) "Self on self-esteem, Defensive Strategies and Social Intelligence in the adolescence”. Social and Behavioural Sciences, Vol.69.2054-2060.

Erwin P. Lacanlale (2013) "Development and validation of a social Intelligence inventory". International Journal of Information and Education Technology, 3(2).263-267.

Malikeh Beheshtifar and Fateme Roasaki (2012) "Role of social Intelligence in organizational leadership”. European Journal of Social Science,28(2).200-206.

Ramesh singh Bartwal (2015) "To study the mental health of senior secondary students in relation to their social intelligence" IOSR Journal Of Humanities And Social Science (IOSR-JHSS). 19(2).06-10.

Ruchi Thakur, Shubhanaganna Sharma and Raj Pathania (2013)"Social Intelligence of Adolescents: A study of Himachal Pradesh”. Volume 7, Student Home Community Science. Stud Home Com Sci, 7(3). 161-166.

Sembiyan. R and Visvanathan.G (2012) "A study on the attitude towards regionalism of college students in relation to social intelligence”, Indian Streams Research Journal. 1(XII).1-4.

Sembiyan. R and Visvanathan.G (2012) "Social Intelligence of college students" volume 4, International journal of current Research. 4(1).231-232.

Sumamlata Saxene and Dr, Rajat Kumat jain (2013) "Social Intelligence of undergraduate students in relation to their gender and subject stream". IOSR journal of Research and method in Education (IOSR - JRME), http:// www.Isor.Jornals.org. 1(1).01-04.

Vipinder Nagra (2014) "Social Intelligence and Adjustment of secondary School students", Indian journal of Research, 3(4).86-87. 